\title{
A 52 month follow-up of functional decline in nursing home residents - degree of dementia contributes
}

\author{
Anne-Sofie Helvik ${ }^{1,2,3^{*}}$, Knut Engedal ${ }^{3}$, Jūrate Šaltytė Benth ${ }^{4,5,6}$ and Geir Selbæk ${ }^{3,6,7}$
}

\begin{abstract}
Background: Few have studied how personal activities of daily living (P-ADL) develop over time in nursing home residents with dementia. Thus, the aim was to study variables associated with the development of P-ADL functioning over a 52-month follow-up period, with a particular focus on the importance of the degree of dementia.

Method: In all, 932 nursing home residents with dementia (Clinical Dementia Rating-CDR- Scale $\geq 1$ ) were included in a longitudinal study with four assessments of P-ADL functioning during 52 months. P-ADL was measured using the Lawton and Brody's Physical Self-Maintenance Scale. Degree of dementia (CDR), neuropsychiatric symptoms and use of psychotropic medication were assessed at the same four time points. Demographic information and information about physical health was included at baseline. Linear regression models for longitudinal data were estimated.

Results: Follow-up time was positively associated with a decline in P-ADL functioning. Degree of dementia at baseline was associated with a decline in P-ADL functioning over time. The association between degree of dementia and P-ADL functioning was strongest at baseline, and then flattened over time. A higher level of neuropsychiatric symptoms such as agitation and apathy and no use of anxiolytics and antidementia medication were associated with a decline in P-ADL functioning at four time points. Higher physical co-morbidity at baseline was associated with a decline in P-ADL functioning.
\end{abstract}

Conclusion: P-ADL functioning in nursing home patients with dementia worsened over time. The worsening was associated with more severe dementia, higher physical comorbidity, agitation, apathy and no use of anxiolytics and antidementia medication. Clinicians should pay attention to these variables (associates) in order to help the nursing home residents with dementia to maintain their level of functioning for as long as possible.

\section{Background}

Dementia is, in most cases, characterized by a progressive decline in cognitive function. In Europe, it is estimated that between six to ten million persons have dementia [1]. The prevalence of dementia increases with age, from approximately $1.5 \%$ in persons aged 60 69 years to $40 \%$ in persons 90 years and older [2]. The prevalence of dementia is found to be high in nursing home residents in the Western countries [3-6]. Studies

\footnotetext{
* Correspondence: Anne-Sofie.Helvik@ntnu.no

${ }^{1}$ Department of Public Health and General Practice, Faculty of Medicine,

Norwegian University of Science and Technology (NTNU), Trondheim,

Norway

${ }^{2}$ St Olav's University Hospital, Trondheim, Norway

Full list of author information is available at the end of the article
}

in Norway have indicated that more than $80 \%$ of nursing home residents have dementia $[7,8]$.

In general, dementia will negatively affect the person's ability both to function adequately in everyday life and to perform personal activities of daily living (P-ADL), such as bathing, dressing, eating, grooming, ambulation/ transferring and toileting [9-17].

Dementia and the accompanying P-ADL impairment increase the risk of being admitted to nursing home care $[18,19]$ as increasing P-ADL impairment increases the need of care. Lower P-ADL functioning increases the burden for the patients, their family, the professional caregivers and society as a whole [15,20,21]. Furthermore, P-ADL impairment in older persons increases the risk of mortality [22-25].

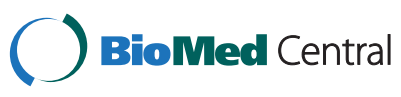

(c) 2014 Helvik et al.; licensee BioMed Central Ltd. This is an Open Access article distributed under the terms of the Creative Commons Attribution License (http://creativecommons.org/licenses/by/2.0), which permits unrestricted use, distribution, and reproduction in any medium, provided the original work is properly credited. The Creative Commons Public Domain Dedication waiver (http://creativecommons.org/publicdomain/zero/1.0/) applies to the data made available in this article, unless otherwise stated. 
Up to now, relatively few studies have explored how $\mathrm{P}$-ADL functioning changes over time in nursing home residents with dementia [26]. An early study explored $\mathrm{P}-\mathrm{ADL}$ decline in nursing home residents without assessing dementia and or cognitive impairment [22]. Others have explored if the presence of dementia (yes/no) in nursing home residents at baseline was important for later P-ADL decline $[23,27,28]$. Diverging results were reported. Furthermore, prospective register studies of nursing home residents with and without dementia have studied the association between P-ADL decline and the degree of cognitive impairment with a follow-up period of three months to one year. These studies found that a decline of P-ADL functioning was explained by the degree of P-ADL impairment and degree of cognitive impairment at baseline [29-32]. None of the register studies explored the importance of medical co-morbidity to a P-ADL decline.

A recent six-month follow-up study of long-term residents with dementia reported that a decline in P-ADL functioning was associated with the patients' degree of dementia [26]. However, this study had excluded the residents with physical co-morbidities and did not study the influence of neuropsychiatric symptoms on P-ADL development. Information about medical co-morbidity and neuropsychiatric symptoms should be included, since studies report that such symptoms may have importance for P-ADL functioning [31,33,34]. Other risk factors for a decline in P-ADL functioning over time in nursing home residents may be age, ethnicity, gender, marital status and education [22,27,28,31,32,35]. Protective factors for a decline in P-ADL have also been reported, such as the longterm use of antidementia medication [20,36,37].

A number of disease specific and generic P-ADL indexes have been developed, validated and found sensitive to small but significant changes in persons' ability to perform P-ADL [20,38]. Even so, several studies of PADL decline in nursing home residents have used single items $[26,32,33,35]$ rather than P-ADL indexes covering a range of P-ADL functions [23,31]. The Physical SelfMaintenance Scale is one of the shorter recommended P-ADL indexes [20], which has been frequently used in Scandinavian studies $[7,8,39,40]$.

To our knowledge no long-term follow-up of nursing home residents has been conducted including both a measure of cognition and physical co-morbidities. Thus, our aim was to study the association between degree of dementia, both at baseline and over more than four years, and the development in P-ADL functioning measured by the Physical Self-Maintenance Scale (P-ADL score), adjusting for a number of other variables know to have an influence on P-ADL functioning in nursing home residents with dementia. We hypothesize that P-ADL functioning in persons with dementia living in nursing homes will decline over time, and that this decline will be associated with a worsening of dementia, the neuropsychiatric symptom load, medication and physical comorbidity.

\section{Method \\ Design}

This was a 52 months prospective study with four assessments. Baseline assessment took place between November 2004 and January 2005. The follow-up assessments took place after 12, 31 and 52 months.

\section{Participants}

All residents in 26 nursing homes in 18 municipalities and four counties in Norway with a stay of a minimum of 14 days were asked to participate in the study. The municipalities were chosen to make the sample representative in terms of municipality size [8]. In all, 1165 residents were eligible. Two residents or their next of kin refused participation, four had important missing information, and 233 had no dementia according to the Clinical Dementia Rating (CDR) scale, i.e. CDR $<1$ [41]. Thus, 932 residents were included in the longitudinal study of P-ADL.

\section{Measures}

The Demographic information age, level of education, marital status and length of stay at inclusion, was collected from the medical records.

The Medical health information was collected from the medical records with the use of diagnoses in the International Statistical Classification of Diseases and Related Health problems $10^{\text {th }}$ Revision (ICD-10). The diagnoses were sorted into diagnostic groups, i.e. stroke-, cardiovascular-, pulmonary-, musculoskeletal-, digestive-, endocrine-, neurological-, genito-urinal- and neoplasm diagnoses [42]. A co-morbidity index was calculated by summing up the occurrence of diagnoses (yes/no) in each of the nine groups of diagnoses.

Sensory loss was registered by two single items for vision and hearing impairment, respectively, i.e. perceived severely impaired or not. No specific measurement was used and the occurrence of vision and hearing impairment are based on the primary professional caregiver's clinical judgement.

Dementia was assessed using the Clinical Dementia Rating (CDR) scale which covers six domains (memory, orientation, judgment and problem solving, community affairs, home and hobbies, and personal care) with five response categories $(0,0.5,1,2,3)[41,43]$. The total score is calculated by means of an algorithm giving priority to memory [41]. Residents with a total score of one or higher were regarded as having dementia [44-46]. In the analysis we used the CDR sum score (sum of boxes), which ranges from 0 to 18 with a higher score indicating 
greater dementia severity. The correlation between the CDR score and the CDR sum of boxes is high. However, due to an increased range of values, the CDR sum of boxes offers important advantages when analyzing the data. [47].

Neuropsychiatric symptoms were assessed using the Neuropsychiatric Inventory (12-item NPI) [48] in a translated and validated Norwegian version [49]. The 12-item inventory covers the following symptoms: delusion, hallucination, agitation/aggression, disinhibition, irritability/ lability, depression/dysphoria, anxiety, apathy/indifference, aberrant motor behaviour, sleep and night-time behaviour disorder and appetite/eating changes. For each symptom, severity (score 1-3) multiplied by frequency (score 1-4) gave a score ranging from one to twelve. Based on a previous principal component analysis, psychosis (delusions, hallucination), agitation (agitation/aggression, disinhibition, irritability) and affective (depression, anxiety) subsyndrome scores were formed by summing the score of the included items [50-53].

Psychotropic medications were grouped according to the ATC code, into antipsychotics (N05A except lithium), antidepressants (N06A), anxiolytics (N05B), hypnotics/ sedatives (N05C) and antidementia medication (N06D) (yes versus no). The information was collected from the medical record of each resident.

Level of functioning in personal Activities of Daily Living (P-ADL), the dependent variable, was measured by the Physical Self-Maintenance Scale (six items, score range 6-30, i.e. P-ADL scale score) [54]. High scores indicate a lower level of functioning.

\section{Procedure}

Prior to the study, 16 research assistants (all registered nurses) attended a two-day training program on how to conduct the interview. A one-day training program was carried out prior to each follow-up assessment. The project leader (GS) was available for consultation while the data were collected. The research assistants collected the data by means of a standardized interview with the primary professional caregiver and by extracting information from the medical records.

Study information was given to the patient and their family members. An explicit consent was not required for enrollment, but the patients and their next of kin were informed in writing that they could refuse to participate at any stage of the study. The study, and the procedure for information and the right to decline participation were approved by the Regional Ethics Committee of Eastern Norway in 2004, the Data Inspectorate and the Directorate for Health and Social Affairs.

\section{Data analysis}

Continuous socio-demographic and clinical characteristics were presented as means and standard deviations (SD), while frequencies and proportions were used for categorical characteristics. A linear regression model was estimated to assess the development in P-ADL throughout the follow-up period of 52 months. As P-ADL consists of repeated measurements, the assumption of independent observations required for ordinary linear regression was violated. Therefore, a linear mixed model containing both linear and second-order time components as fixed effects (growth model) as well as random effects for intercepts and slopes for time was estimated first. Such a model accounts for correlations due to repeated measurements and accommodates any degree of imbalance in longitudinal data. That is, the model is particularly suited for analysing data with missing values and drop-outs due to death, for instance. The SAS MIXED procedure was used to fit the model. The main independent variable, degree of dementia assessed with CDR sum of boxes, and interaction term between degree of dementia and time were then entered into the model as fixed effects. Two different models with

Table 1 Characteristics of study sample at baseline ( $\mathrm{N}=932$ )

\begin{tabular}{|c|c|c|c|}
\hline \multicolumn{2}{|l|}{ Demographic } & \multicolumn{2}{|c|}{ Total } \\
\hline Previous length of stay (days) & Mean (SD) & 928.9 & $(910.1)$ \\
\hline Women & N (\%) & 686 & (73.6) \\
\hline Age (year) & Mean (SD) & 84.5 & $(7.5)$ \\
\hline Single as marital status & N (\%) & 714 & $(79.4)$ \\
\hline Ten years of school or less & N (\%) & 673 & $(74.1)$ \\
\hline \multicolumn{4}{|l|}{ Information on somatic health } \\
\hline Co-morbidity index ${ }^{1}$ & Mean (SD) & 1.8 & $(1.3)$ \\
\hline Severely impaired hearing & N (\%) & 126 & (13.6) \\
\hline Severely impaired vision & N (\%) & 139 & (14.9) \\
\hline \multicolumn{4}{|l|}{ Cognitive functioning } \\
\hline CDR sum of boxes & Mean (SD) & 13.1 & $(4.0)$ \\
\hline \multicolumn{4}{|c|}{$\begin{array}{l}\text { Behavioral and psychological sub-syndromes } \\
\text { of dementia (12-item NPI) }\end{array}$} \\
\hline Agitation & Mean (SD) & 6.5 & $(8.2)$ \\
\hline Psychosis & Mean (SD) & 3.2 & $(5.4)$ \\
\hline Affective & Mean (SD) & 3.7 & $(5.4)$ \\
\hline Apathy & Mean (SD) & 2.4 & (3.8) \\
\hline \multicolumn{4}{|l|}{ Psychotropic medication ${ }^{2}$} \\
\hline Antipsychotics & N (\%) & 241 & (25.9) \\
\hline Antidepressants & N (\%) & 364 & (39.1) \\
\hline Anxiolytics & N (\%) & 221 & $(23.7)$ \\
\hline Sedatives & N (\%) & 245 & (26.3) \\
\hline Antidementia & N (\%) & 126 & (13.5) \\
\hline
\end{tabular}

$\mathrm{CDR}=$ Clinical Dementia Rating Scale.

${ }^{1}$ The co-morbidity index was calculated by summing up the occurrence of diagnoses (yes/no) in nine groups of diagnoses.

${ }^{2}$ The cumulative proportion of psychotropic medication is higher than 100 due to combinational use of psychotropic medication. 
respect to adjustment were further estimated. In both models, adjustment variables were demographic characteristics (length of stay prior to baseline, age, gender, education, and marital status), physical health information (co-morbidity index, severe sensory loss), neuropsychiatric symptoms and use of psychotropic medications. Length of stay, age, and gender were defined to be the confounders, while the other adjustment variables were defined as secondary independent variables. The first model contained adjustment variables all measured at baseline. The second model included demographic characteristics, somatic health difficulties at baseline, while neuropsychiatric symptoms of dementia and use of psychotropic medications were entered as longitudinal variables. The following modelling strategy was employed. Firstly, a model containing all defined secondary independent variables was reduced by applying Akaike's Information Criteria (AIC). The least significant secondary independent variables were removed from the model one at a time and AIC was calculated at each step. The model with the smallest value of AIC was chosen. Secondly, the CDR sum of boxes, interaction term between the CDR sum of boxes and time, and the three confounders were entered into the reduced model and a final model was estimated. Lastly, to assess eventual gender-specific differences, interactions between gender and CDR sum of boxes, age, and education were entered into the final model. However, none of them were significant and therefore excluded. The results of the regression analysis were tabulated as coefficients with the corresponding 95\% confidence intervals (CI). Regression coefficients were used to estimate the P-ADL score for each time point from an unadjusted model as well as from both adjusted models at the median baseline CDR sum of boxes value and were presented graphically.

Analyses were performed in SAS v9.2 and SPSS v20. P-values below 0.05 were considered statistically significant. All tests were two-sided.

\section{Results}

Sample characteristics

At baseline, the mean (SD) age and length of stay for the participants were 84.5 (7.5) years and 932 (910.1) days,

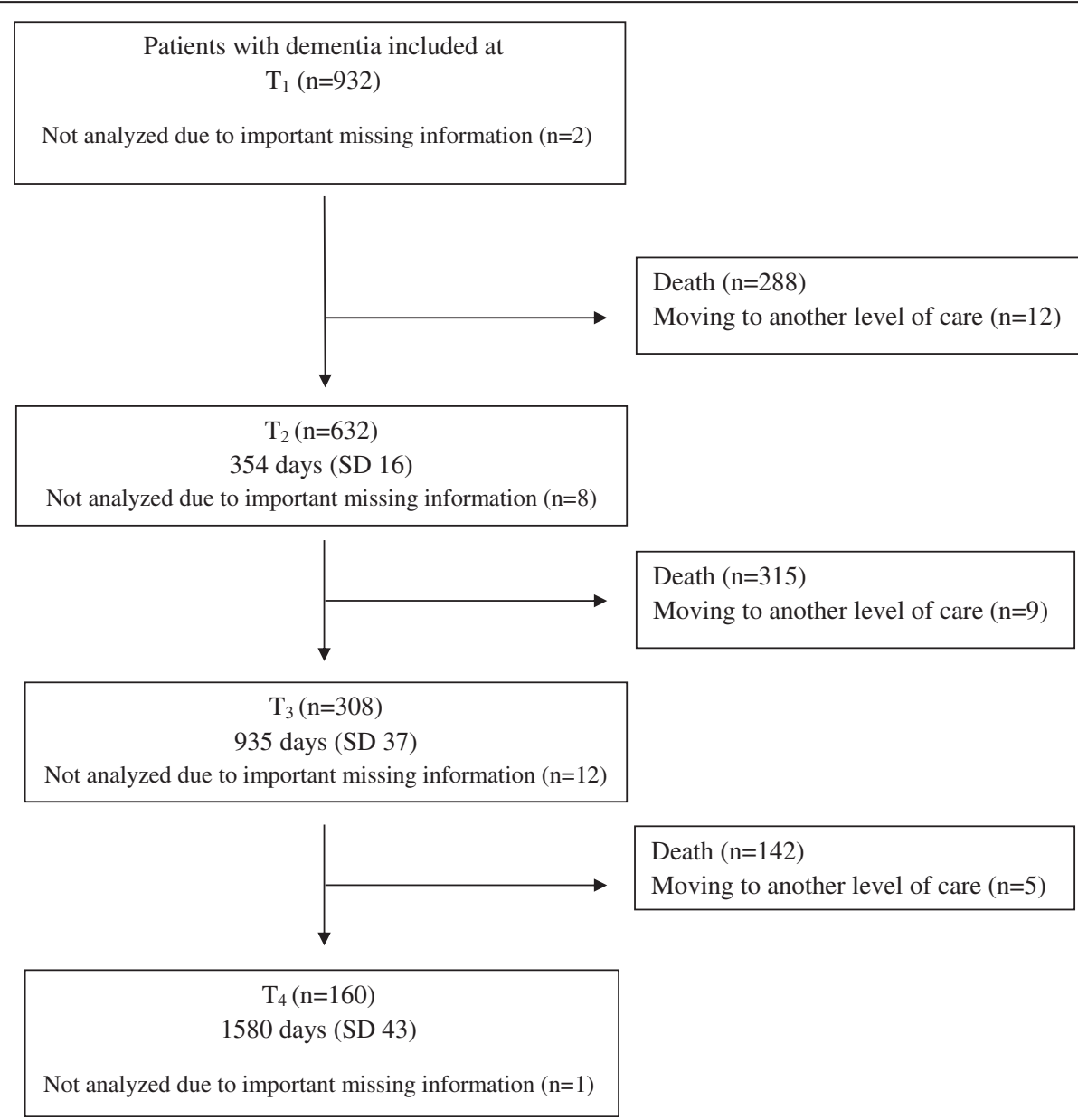

Figure 1 Flow chart of participants from baseline $\left(T_{1}\right)$ to last follow-up up $\left(T_{4}\right)$, with mean (SD) follow-up time at each assessment. 
Table 2 P-ADL score at four time points

\begin{tabular}{lcc}
\hline Time point & Min, Max & Mean (SD) \\
\hline T1 & 6,29 & $18.8(5.3)$ \\
T2 & 7,30 & $19.6(5.2)$ \\
T3 & 7,30 & $20.8(4.8)$ \\
T4 & 9,29 & $21.6(4.6)$ \\
\hline
\end{tabular}

respectively (see Table 1). In all, $246(26.4 \%)$ of the residents were men and the mean score of the co-morbidity index was 1.8 (SD 1.3, ranging from 0 to 6 groups of diagnoses). The mean (SD) baseline CDR sum of boxes was 13.1 (4.0). Of the 932 participants at baseline, 160 $(17.2 \%)$ participants were available at the fourth follow-up (see Figure 1). The individual development of P-ADL throughout the follow-up period and the mean P-ADL at four time points (see Table 2) indicated worsening in P-ADL functioning, which was confirmed by the secondorder growth model. The positive linear time component (95\% CI) of 0.14 (0.12; 0.16) shows that the P-ADL functioning declined over time, and negative second-order time component of $-0.001(-0.001:-0.0005)$ shows that the mean rate of decline decreased with time.

\section{The importance of degree of dementia for P-ADL} functioning

The importance of degree of dementia for P-ADL functioning over time was studied in two adjusted models. In

Table 3 Model 1: Effects of cognitive impairment (CDR sum of boxes) measured at baseline on P-ADL level over time estimated by linear mixed model with random effects for intercepts and time

\begin{tabular}{|c|c|c|c|c|}
\hline \multirow{2}{*}{ In dependent variables } & \multicolumn{2}{|c|}{ Unadjusted regression coefficients } & \multicolumn{2}{|c|}{ Adjusted regression coefficients } \\
\hline & Coeff. $(95 \% \mathrm{Cl})$ & p-value & Coeff. $(95 \% \mathrm{Cl})$ & $\mathrm{p}$-value \\
\hline \multicolumn{5}{|l|}{ Effect of main variables $^{1}$} \\
\hline Time & $0.19(0.15 ; 0.24)$ & $<0.001$ & $0.20(0.16 ; 0.25)$ & $<0.001$ \\
\hline Time* time & $-0.001(-0.001 ;-0.0005)$ & $<0.001$ & $-0.001(-0.002 ;-0.001)$ & $<0.001$ \\
\hline CDR sum of boxes & $0.72(0.65 ; 0.79)$ & $<0.001$ & $0.61(0.53 ; 0.69)$ & $<0.001$ \\
\hline Time* CDR sum of boxes & $-0.004(-0.007 ;-0.001)$ & 0.007 & $-0.004(-0.007 ;-0.001)$ & 0.013 \\
\hline \multicolumn{5}{|c|}{ Effect of additional variables at baseline $e^{2}$} \\
\hline Length of stay & $0.002(0.001 ; 0.002)$ & $<0.001$ & $0.001(0.001 ; 0.001)$ & $<0.001$ \\
\hline \multicolumn{5}{|l|}{ Socio -demographic information } \\
\hline Age (years) & $-0.02(-0.06 ; 0.02)$ & 0.312 & $-0.05(-0.09 ;-0.01)$ & 0.007 \\
\hline Women & $-0.33(-1.03 ; 0.38)$ & 0.362 & $-0.62(-1.25 ; 0.01)$ & 0.054 \\
\hline Single & $-0.80(-1.58 ;-0.03)$ & 0.042 & $-0.72(-1.41 ;-0.03)$ & 0.041 \\
\hline Ten years of education or less & $0.46(-0.25 ; 1.17)$ & 0.206 & $0.48(-0.12 ; 1.07)$ & 0.117 \\
\hline \multicolumn{5}{|l|}{ Somatic health difficulties } \\
\hline Co-morbidity index & $0.21(-0.04 ; 0.46)$ & 0.100 & $0.32(0.11 ; 0.53)$ & 0.003 \\
\hline No severe vision impairment & $1.65(0.77 ; 2.53)$ & $<0.001$ & $0.93(0.19 ; 1.67)$ & 0.014 \\
\hline No severe hearing impairment & $-0.79(-1.70 ; 0.13)$ & 0.091 & $-0.12(-0.90 ; 0.66)$ & 0.765 \\
\hline \multicolumn{5}{|c|}{ Degree of neuropsychiatric problems } \\
\hline Agitation sub-syndrome & $0.08(0.04 ; 0.12)$ & $<0.001$ & $0.01(-0.0 ; 0.04)$ & 0.546 \\
\hline Psychosis sub- syndrome & $0.04(-0.02 ; 0.10)$ & 0.150 & & \\
\hline Affective sub-syndrome & $0.02(-0.04 ; 0.07)$ & 0.602 & & \\
\hline Apathy & $0.35(0.27 ; 0.43)$ & $<0.001$ & $0.10(0.03 ; 0.18)$ & 0.007 \\
\hline \multicolumn{5}{|l|}{ Use of psychotropic medication } \\
\hline Antipsychotics & $0.72(0.01 ; 1.42)$ & 0.046 & $-0.08(-0.69 ; 0.53)$ & 0.802 \\
\hline Antidepressants & $-0.56(-1.19 ; 0.07)$ & 0.081 & $-0.33(-0.86 ; 0.20)$ & 0.225 \\
\hline Anxiolytics & $-0.28(-1.01 ; 0.44)$ & 0.443 & $-0.70(-1.31 ;-0.10)$ & 0.024 \\
\hline Sedatives & $-0.65(-1.36 ; 0.05)$ & 0.070 & $-0.12(-0.70 ; 0.47)$ & 0.701 \\
\hline Cognitive enhancers & $-3.23(-4.09 ;-2.36)$ & $<0.001$ & $-1.81(-2.58 ;-1.05)$ & $<0.001$ \\
\hline
\end{tabular}

${ }^{1}$ The coefficients of the main effect variables (time, squared time, CDR sum of boxes, and interaction between time and CDR sum of boxes) unadjusted for other independent variables.

${ }^{2}$ The coefficients $(95 \% \mathrm{Cl})$ for single independent variables from the model containing only linear and second-order time components.

* $=$ Multiplied with Bold data indicate $\mathrm{p}$-value $<0.05$. 
the first adjusted model (Table 3), the association between degree of dementia at baseline and P-ADL functioning over time was assessed. There was a significant second-order time trend in P-ADL functioning, and more severe dementia at baseline was associated with declined P-ADL functioning over time. The association between degree of dementia and P-ADL functioning was strongest at baseline, the development in time flattened and the association between the baseline degree of dementia and the decline in P-ADL functioning decreased with time.

Table 4 presents the results from the second model finding degree of dementia at each time point being associated with poorer P-ADL functioning at the same time points. As in the first model, there was a decline in P-ADL functioning throughout the follow-up period. Furthermore, as in the first model, the association between degree of dementia and P-ADL functioning was strongest at baseline, the development in time flattened and the association between baseline degree of dementia on decline in P-ADL functioning became weaker with time.

In addition, longer length of stay, being married, having a higher comorbidity index score and having severely impaired vision at baseline were associated with worse P-ADL functioning through the observation period.

Table 4 Model 2: Effects of cognitive impairment (CDR sum of boxes) measured at four time points on P-ADL level at the same time points estimated by linear mixed model with random effects for intercepts and time

\begin{tabular}{|c|c|c|c|c|}
\hline & \multicolumn{2}{|c|}{ Unadjusted regression coefficients } & \multicolumn{2}{|c|}{ Adjusted regression coefficients } \\
\hline & Coeff. $(95 \% \mathrm{Cl})$ & $\mathrm{p}$-value & Coeff. (95\% Cl) & p-value \\
\hline \multicolumn{5}{|l|}{ Effect of main variables ${ }^{1}$} \\
\hline Time & $0.06(0.02 ; 0.10)$ & 0.002 & $0.18(0.14 ; 0.22)$ & $<0.001$ \\
\hline Time* time & $0.001(-0.001 ;-0.001)$ & $<0.001$ & $-0.001(-0.001 ;-0.0004)$ & $<0.001$ \\
\hline CDR sum of boxes (at 4 time points) & $0.48(0.43 ; 0.54)$ & $<0.001$ & $0.60(0.52 ; 0.67)$ & $<0.001$ \\
\hline Time $^{*}$ CDR sum of boxes & $0.003(0.001 ; 0.006)$ & 0.007 & $-0.003(-0.006 ;-0.0006)$ & 0.019 \\
\hline \multicolumn{5}{|c|}{ Effect of additional variables at baseline ${ }^{2}$} \\
\hline Length of stay & $0.002(0.001 ; 0.002)$ & $<0.001$ & $0.001(0.001 ; 0.0011)$ & $<0.001$ \\
\hline \multicolumn{5}{|l|}{ Socio-demographic information } \\
\hline Age (years) & $-0.02(-0.06 ; 0.02)$ & 0.312 & $-0.04(-0.08 ;-0.004)$ & 0.030 \\
\hline Women & $-0.33(-1.03 ; 0.38)$ & 0.362 & $-0.51(-1.13 ; 0.11)$ & 0.108 \\
\hline Single & $-0.80(-1.58 ;-0.03)$ & 0.042 & $-0.78(-1.45 ;-0.11)$ & 0.023 \\
\hline Ten years of education or less & $0.46(-0.25 ; 1.17)$ & 0.206 & $0.45(-0.14 ; 1.03)$ & 0.136 \\
\hline \multicolumn{5}{|l|}{ Somatic health difficulties } \\
\hline Co-morbidity index & $0.21(-0.04 ; 0.46)$ & 0.100 & $0.35(0.15 ; 0.56)$ & 0.001 \\
\hline No severe vision impairment & $1.65(0.77 ; 2.53)$ & $<0.001$ & $0.88(0.14 ; 1.61)$ & 0.019 \\
\hline No severe hearing impairment & $-0.79(-1.70 ; 0.13)$ & 0.091 & $-0.16(-0.92 ; 0.61)$ & 0.689 \\
\hline \multicolumn{5}{|c|}{ Effect of additional variables assessed at 4 time-points ${ }^{2}$} \\
\hline \multicolumn{5}{|l|}{ Degree of neuropsychiatric problems } \\
\hline Agitation sub-syndrome & $0.04(0.02 ; 0.06)$ & $<0.001$ & $0.03(0.003 ; 0.05)$ & 0.026 \\
\hline Psychosis sub- syndrome & $0.02(-0.01 ; 0.06)$ & 0.173 & & \\
\hline Affective sub-syndrome & $0.01(-0.03 ; 0.04)$ & 0.614 & $-0.03(-0.06 ; 0.01)$ & 0.166 \\
\hline Apathy & $0.20(0.15 ; 0.24)$ & $<0.001$ & $0.12(0.08 ; 0.17)$ & $<0.001$ \\
\hline \multicolumn{5}{|l|}{ Use of psychotropic medication } \\
\hline Antipsychotics & $0.77(0.31 ; 1.23)$ & 0.001 & $0.41(-0.03 ; 0.86)$ & 0.067 \\
\hline Antidepressants & $-0.63(-1.05 ;-0.20)$ & 0.004 & $-0.40(-0.80 ; 0.003)$ & 0.052 \\
\hline Anxiolytics & $-0.67(-1.15 ;-0.20)$ & 0.005 & $-0.77(-1.22 ;-0.32)$ & 0.001 \\
\hline Sedatives & $-0.29(-0.75 ; 0.17)$ & 0.213 & & \\
\hline Cognitive enhancers & $-2.31(-2.94 ;-1.67)$ & $<0.001$ & $-1.72(-2.33 ;-1.11)$ & $<0.001$ \\
\hline
\end{tabular}

${ }^{1}$ The coefficients of the main effect variables (time, squared time, CDR sum of boxes, and interaction between time and CDR sum of boxes) unadjusted for other independent variables.

${ }^{2}$ The coefficients $(95 \% \mathrm{Cl})$ for single independent variables from the model containing only linear and second-order time components.

* $=$ Multiplied with Bold data indicate p-value $<0.05$. 
Among the independent variables with assessments at all four time points included in the analysis, a higher agitation sub-syndrome score and apathy score, as well as not using anxiolytics and antidementia medication were associated with lower P-ADL functioning at the same time points.

Figure 2 illustrates the unadjusted P-ADL development over the follow-up period as well as P-ADL development adjusted in two different ways (two models). Independently of the adjustments made, there is an upward trend in the P-ADL values over time, i.e. the $\mathrm{P}$-ADL functioning declines, but the rate of decline flattened during follow-up. The degree of decline in P-ADL functioning during follow-up was moderated using the adjusted models.

\section{Discussion}

This follow-up study of 932 nursing home residents with dementia found that degree of dementia at baseline and the course of dementia as measured by the CDR during follow-up was significantly associated with lower P-ADL functioning. The rate of decline in P-ADL functioning explained by the degree of dementia decreased during follow-up. Independently of the adjustments made, there is a decline in P-ADL function over time and the rate of decline due to time of follow-up decreased during follow-up.

Other authors have pointed to a relationship between more severe dementia and worse P-ADL both among older hospitalized patients [11], community dwelling older persons $[9,10]$ and in nursing home residents $[23,26,28]$. However, few have studied the P-ADL development and slope of development of P-ADL by time and degree of dementia in nursing home residents with dementia using several years of follow-up. Our results are supported by a six month follow-up study among residents with dementia. In this study, the mean P-ADL reduction increased in residents with severe dementia [26]. Another nursing home study in the USA, which followed residents with and without dementia for one year, explored if the degree of cognitive impairment at baseline affected the rate of P-ADL decline during follow-up [31]. This study with a follow-up period of 12 months did not find that cognitive impairment at baseline affected the rate of decline in P-ADL functioning over time, but a low P-ADL functioning at baseline was explained by baseline cognition [31]. However, a recent Swedish community study of older persons diagnosed with minimal cognitive impairment or Alzheimer disease reported that the rate of decline in P-ADL functioning due to degree of cognitive impairment decreased during the follow-up period of eight years, i.e. the slope of decline in P-ADL functioning leveled off [55]. Our results as well as the results of the Swedish study indicate the importance of "tailoring" the care for persons with dementia as the dementia disorder progress and the $\mathrm{P}$-ADL decrease. The tailoring of care according to the patients increasing needs will probably increase the quality of life for the persons with dementia [56].

Interestingly, we found that worse P-ADL functioning at each time point was associated with a higher level of neuropsychiatric symptoms at the same time points, i.e. higher agitation sub-syndrome or apathy symptoms. Our findings are in line with previous research. Previously, it has been reported that a higher baseline sum score of neuropsychiatric symptoms is associated with a higher tendency for falls the coming year [33] and apathy symptoms have been reported to be associated with more motor and process skills difficulties [34]. The present study found an association between higher P-ADL functioning and the use of anti-dementia medication. This is

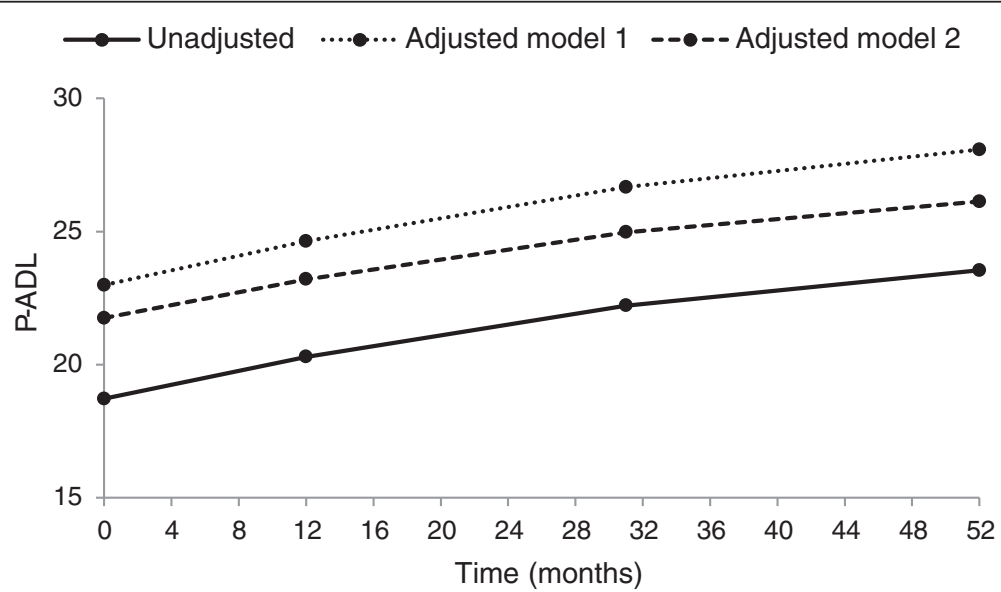

Figure 2 Development of P-ADL score in time, unadjusted, adjusted in Model 1 and adjusted in Model 2. P-ADL values demonstrate a significant second-order time trend indicating that the P-ADL functioning declines at the start of the follow-up period and flattens out later. Adjustment of time trend for clinical and demographic characteristics resulted only in minor changes. 
in line with the findings of many randomized controlled trials that have shown an effect of treatment with antidementia medication on P-ADL [20,36,37]. However, residents using anti-dementia medication may have higher P-ADL functioning of other reasons which we did not adjust for. Why the use of anxiolytics should have a positive effect on P-ADL functioning is not easy to explain, but it could be that by reducing anxiety in patients with dementia, especially in those with agitation, their concentration and activity can improve.

In contrast to prospective studies which have not studied the importance of physical health in nursing home residents for the association between degree of dementia and P-ADL functioning or have excluded residents with co-morbid physical disorders [26,29-32], the present study adjusted for co-morbid physical disorders. In line with previous known risk factors for the decline of P-ADL over time, we found that higher co-morbidity and severe vision impairment at baseline were associated with lower P-ADL functioning at each time point [10]. This knowledge should also be used when tailoring the care for persons with dementia according to their needs.

Even if the study has a number of advantages, such as using a well-known, internationally accepted P-ADL measure, having a high number of baseline residents and adjustment for a high number of variables of potential importance to the outcome, such as health and demographic variables, there are some limitations that need to be addressed. Firstly, associations found in our study should be interpreted with caution since our design does not allow for inferences about causality.

Secondly, assessments of P-ADL functioning of older persons in a longitudinal study with several follow-ups over a period of years are statistically challenging. Repeatedly measured P-ADL functioning for the same individuals implies dependency in data. Having a large number of drop-outs, due to death leads to a varying number of observations per individual and generates unbalanced longitudinal data. Furthermore, a number of the independent variables in the adjusted models are time-varying. However, the linear mixed model used is particularly flexible with respect to these issues. The model handles any degree of imbalance in data by including all available observations. It also accounts for the correlations among repeated measurements in a relatively parsimonious way.

Thirdly, even if information about use of each category of psychotropic medications were available, we did not have the dosages of the psychotropic medications. Moreover, use of a well-known comorbidity index, f. ex. Charlson comorbidity index $[57,58]$ rather than the comorbidity index we applied would have been more informative. Lastly, it may be questioned if the Minimal Mental State Examination $[59,60]$ widely used and accepted could have been a better choice for the assessment dementia than
CDR which we applied. The MMSE has the advantage of providing a direct measure of cognition. However, in a sample as ours many will have scores in the lower range, and previous research has questioned the ability of the MMSE to differentiate between persons with severe dementia [61]. As a consequence of these limitations, we cannot rule out that there are confounders which we have not adjusted adequately for.

\section{Conclusion}

In a large-scale longitudinal nursing home study among patients with dementia, using four assessments during a period of 52 months, we found that P-ADL functioning worsened over time. The worsening of P-ADL functioning was associated with a higher baseline degree of dementia and with an increasing degree of dementia during followup. The importance of degree of dementia and follow-up time for degree of decline in P-ADL functioning decreased during follow-up.

Clinicians should pay attention to the associates of P-ADL functioning identified in our study in order to help the nursing home residents with dementia maintain their level of functioning as long as possible.

\section{Competing interests}

The authors declare that they have no competing interests.

\section{Authors' contributions}

GS and KE designed the study, and GS was responsible for the data collection and quality as e study results. JSB analyzed the majority of the data for this manuscript. ASH has analyzed sections of the data and drafted the manuscript. All authors participated in the interpretation of the study results and in editing the manuscript, and have read and approved the final manuscript.

\section{Acknowledgment}

The data collection was funded by unrestricted grants from Eastern Norway Regional Health authorities.

\section{Author details}

${ }^{1}$ Department of Public Health and General Practice, Faculty of Medicine, Norwegian University of Science and Technology (NTNU), Trondheim, Norway. ${ }^{2}$ St Olav's University Hospital, Trondheim, Norway. ${ }^{3}$ The Norwegian Centre for Dementia Research, Vestfold Health Trust, Tønsberg, Norway. ${ }^{4}$ Institute of Clinical Medicine, Campus Ahus, University of Oslo, Oslo, Norway. ${ }^{5} \mathrm{H} \varnothing \mathrm{KH}$, Research Centre, Akershus University Hospital, Lørenskog, Norway. ${ }^{6}$ Centre for Old Age Psychiatric Research, Innlandet Hospital Trust, Ottestad, Norway. ${ }^{7}$ Akershus University Hospital, Lørenskog, Norway.

Received: 27 January 2014 Accepted: 1 April 2014

Published: 10 April 2014

\section{References}

1. Wimo A, Jonsson L, Gustavsson A, McDaid D, Ersek K, Georges J, Gulacsi L, Karpati K, Kenigsberg P, Valtonen $\mathrm{H}$ : The economic impact of dementia in Europe in 2008-cost estimates from the Eurocode project. Int J Geriatr Psychiatry 2011, 26:825-832.

2. Qiu C, De R, Fratiglioni L: The epidemiology of the dementias: an update. Curr Opin Psychiatry 2007, 20:380-385.

3. Sandman PO, Wallblom A: Characteristics of the demented living in different settings in Sweden. Acta Neurol Scand Supp/ 1996, 168:96-100.

4. Seitz D, Purandare N, Conn D: Prevalence of psychiatric disorders among older adults in long-term care homes: a systematic review. Int Psychogeriatr 2010, 22:1025-1039. 
5. Kowalska J, Rymaszewska J, Szczepanska-Gieracha J: Occurrence of cognitive impairment and depressive symptoms among the elderly in a nursing home facility. Adv Clin Exp Med 2013, 22:111-117.

6. Schaufele M, Kohler L, Hendlmeier I, Hoell A, Weyerer S: Prevalence of dementia and medical care in German nursing homes: a nationally representative survey. Psychiatr Prax 2013, 40:200-206.

7. Bergh S, Holmen J, Saltvedt I, Tambs K, Selbaek G: Dementia and neuropsychiatric symptoms in nursing-home patients in Nord-Trondelag County. Tidsskr Nor Laegeforen 2012, 132:1956-1959.

8. Selbaek G, Kirkevold O, Engedal K. The prevalence of psychiatric symptoms and behavioural disturbances and the use of psychotropic drugs in Norwegian nursing homes. Int J Geriatr Psychiatry 2007, 22:843-849.

9. Barberger-Gateau P, Fabrigoule C: Disability and cognitive impairment in the elderly. Disabil Rehabil 1997, 19:175-193.

10. Stuck AE, Walthert JM, Nikolaus T, Bula CJ, Hohmann C, Beck JC: Risk factors for functional status decline in community-living elderly people: a systematic literature review. Soc Sci Med 1999, 48:445-469.

11. Hoogerduijn JG, Schuurmans MJ, Duijnstee MS, de Rooij SE, Grypdonck MF: A systematic review of predictors and screening instruments to identify older hospitalized patients at risk for functional decline. J Clin Nurs 2007 16:46-57.

12. Bennett HP, Corbett AJ, Gaden S, Grayson DA, Kril JJ, Broe GA: Subcortical vascular disease and functional decline: a 6-year predictor study. J Am Geriatr Soc 2002, 50:1969-1977.

13. Black SA, Rush RD: Cognitive and functional decline in adults aged 75 and older. J Am Geriatr Soc 2002, 50:1978-1986.

14. Sauvaget C, Yamada M, Fujiwara S, Sasaki H, Mimori Y: Dementia as a predictor of functional disability: a four-year follow-up study. Gerontology 2002, 48:226-233.

15. Feldman HH, Jacova C: Mild cognitive impairment. Am J Geriatr Psychiatry 2005, 13:645-655.

16. Leoutsakos JM, Han D, Mielke MM, Forrester SN, Tschanz JT, Corcoran CD, Green RC, Norton MC, Welsh-Bohmer KA, Lyketsos CG: Effects of general medical health on Alzheimer's progression: the Cache County Dementia Progression Study. Int Psychogeriatr 2012, 24:1561-1570.

17. Helvik A-S, Selbaek G, Engedal K: Functional decline in older adults one year after hospitalization. Arch Gerontol Geriatr 2013, 53:305-310.

18. Thygesen E, Saevareid HI, Lindstrom TC, Nygaard HA, Engedal K: Predicting needs for nursing home admission - does sense of coherence delay nursing home admission in care dependent older people? A longitudinal study. Int J Older People Nurs 2009, 4:12-21.

19. Hirdes JP, Poss JW, Curtin-Telegdi N: The Method for Assigning Priority Levels (MAPLe): a new decision-support system for allocating home care resources. BMC Med 2008, 6:9.

20. Potkin SG: The ABC of Alzheimer's disease: $A D L$ and improving day-to-day functioning of patients. Int Psychogeriatr 2002, 14(Suppl 1):7-26.

21. Williams BC, Fries BE, Foley WJ, Schneider D, Gavazzi M: Activities of daily living and costs in nursing homes. Health Care Financ Rev 1994, 15:117-135

22. Bliesmer MM, Smayling M, Kane RL, Shannon I: The relationship between nursing staffing levels and nursing home outcomes. J Aging Health 1998, 10:351-371

23. Gillen $\mathrm{P}$, Spore $\mathrm{D}, \mathrm{Mor} \mathrm{V}$, Freiberger W: Functional and residential status transitions among nursing home residents. J Gerontol A Biol Sci Med Sci 1996, 51:M29-M36.

24. Nakazawa A, Nakamura K, Kitamura K, Yoshizawa Y: Association between activities of daily living and mortality among institutionalized elderly adults in Japan. J Epidemiol 2012, 22:501-507.

25. van Dijk PT, Mehr DR, Ooms ME, Madsen R, Petroski G, Frijters DH, Pot AM, Ribbe MW: Comorbidity and 1-year mortality risks in nursing home residents. J Am Geriatr Soc 2005, 53:660-665.

26. Carpenter Gl, Hastie CL, Morris JN, Fries BE, Ankri J: Measuring change in activities of daily living in nursing home residents with moderate to severe cognitive impairment. BMC Geriatr 2006, 6:7.

27. Stark AJ, Kane RL, Kane RA, Finch M: Effect on physical functioning of care in adult foster homes and nursing homes. Gerontologist 1995, 35:648-655.

28. Ang YH, Au SY, Yap LK, Ee CH: Functional decline of the elderly in a nursing home. Singapore Med J 2006, 47:219-224

29. Snowden M, McCormick W, Russo J, Srebnik D, Comtois K, Bowen J, Teri L, Larson EB: Validity and responsiveness of the minimum data set. J Am Geriatr Soc 1999, 47:1000-1004.
30. McConnell ES, Branch LG, Sloane RJ, Pieper CF: Natural history of change in physical function among long-stay nursing home residents. Nurs Res 2003, 52:119-126.

31. McConnell ES, Pieper CF, Sloane RJ, Branch LG: Effects of cognitive performance on change in physical function in long-stay nursing home residents. J Gerontol A Biol Sci Med Sci 2002, 57:M778-M784.

32. Wang J, Kane RL, Eberly LE, Virnig BA, Chang LH: The effects of resident and nursing home characteristics on activities of daily living. J Gerontol A Biol Sci Med Sci 2009, 64:473-480.

33. Sylliaas $H$, Selbaek $G$, Bergland A: Do behavioral disturbances predict falls among nursing home residents? Aging Clin Exp Res 2012, 24:251-256.

34. Bouwens SF, van Heugten CM, Aalten P, Wolfs CA, Baarends EM, van Menxel DA, Verhey FR: Relationship between measures of dementia severity and observation of daily life functioning as measured with the Assessment of Motor and Process Skills (AMPS). Dement Geriatr Cogn Disord 2008, 25:81-87.

35. Gill TM, Gahbauer EA, Han L, Allore HG: Functional trajectories in older persons admitted to a nursing home with disability after an acute hospitalization. J Am Geriatr Soc 2009, 57:195-201.

36. Gauthier S, Lopez OL, Waldemar G, Jones RW, Cummings J, Zhang R, Schindler R, Schwam E: Effects of donepezil on activities of daily living: integrated analysis of patient data from studies in mild, moderate and severe Alzheimer's disease. Int Psychogeriatr 2010, 22:973-983.

37. Peron EP, Gray SL, Hanlon JT: Medication use and functional status decline in older adults: a narrative review. Am J Geriatr Pharmacother 2011, 9:378-391.

38. Bennett JA: Activities of daily living: old-fashioned or still useful? J Gerontol Nurs 1999, 25:22-29.

39. Barca ML, Engedal K, Laks J, Selbaek G: A 12 months follow-up study of depression among nursing-home patients in Norway. J Affect Disord 2010, 120:141-148.

40. Helvik A-S, Skancke RH, Selbaek G: Screening for depression in elderly medical inpatients from rural area of Norway: prevalence and associated factors. Int J Geriatr Psychiatry 2010, 25:150-159.

41. Hughes CP, Berg L, Danziger WL, Coben LA, Martin RL: A new clinical scale for the staging of dementia. Br J Psychiatry 1982, 140:566-572.

42. Barca ML, Selbaek G, Laks J, Engedal K: The pattern of depressive symptoms and factor analysis of the Cornell Scale among patients in Norwegian nursing homes. Int J Geriatr Psychiatry 2008, 23:1058-1065.

43. Morris JC: The Clinical Dementia Rating (CDR): current version and scoring rules. Neurology 1993, 43:2412-2414.

44. Engedal $K$, Haugen P: The prevalence of dementia in a sample of elderly Norwegians. Int J Geriatric Psychiatr 1993, 8:565-570.

45. Nygaard HA, Naik M, Ruths S: Mental impairment in nursing home residents]. Tidsskr Nor Laegeforen 2000, 120:3113-3116.

46. Waite L, Grayson D, Jorm AF, Creasey H, Cullen J, Bennett H, Casey B, Broe GA: Informant-based staging of dementia using the clinical dementia rating. Alzheimer Dis Assoc Disord 1999, 13:34-37.

47. O'Bryant SE, Waring SC, Cullum CM, Hall J, Lacritz L, Massman PJ, Lupo PJ, Reisch JS, Doody R: Staging dementia using clinical dementia rating scale sum of boxes scores: a Texas Alzheimer's research consortium study. Arch Neurol 2008, 65:1091-1095.

48. Cummings JL: The Neuropsychiatric inventory: assessing psychopathology in dementia patients. Neurology 1997, 48:S10-S16.

49. Selbaek $\mathrm{G}$, Kirkevold $\mathrm{O}$, Sommer $\mathrm{OH}$, Engedal $\mathrm{K}$ : The reliability and validity of the Norwegian version of the Neuropsychiatric Inventory, nursing home version (NPI-NH). Int Psychogeriatr 2008, 20:375-382.

50. Colombo M, Vitali S, Cairati M, Vaccaro R, Andreoni G, Guaita A: Behavioral and psychotic symptoms of dementia (BPSD) improvements in a special care unit: a factor analysis. Arch Gerontol Geriatr 2007, 44(Suppl 1):113-120.

51. Zuidema SU, de Jonghe JF, Verhey FR, Koopmans RT: Neuropsychiatric symptoms in nursing home patients: factor structure invariance of the Dutch nursing home version of the neuropsychiatric inventory in different stages of dementia. Dement Geriatr Cogn Disord 2007, 24:169-176.

52. Selbaek G, Engedal K, Benth JS, Bergh S: The course of neuropsychiatric symptoms in nursing-home patients with dementia over a 53-month follow-up period. Int Psychogeriatr 2014, 26:81-91.

53. Selbaek G, Engedal K: Stability of the factor structure of the Neuropsychiatric inventory in a 31-month follow-up study of a large sample of nursing-home patients with dementia. Int Psychogeriatr 2012, 24:62-73. 
54. Lawton MP, Brody EM: Assessment of older people: self-maintaining and instrumental activities of daily living. Gerontologist 1969, 9:179-186.

55. Handels RL, Xu W, Rizzuto D, Caracciolo B, Wang R, Winblad B, Verhey FR, Severens JL, Fratiglioni L, Joore MA, Wimo A: Natural progression model of cognition and physical functioning among people with mild cognitive impairment and Alzheimer's disease. J Alzheimers Dis 2013, 37:357-365.

56. Bryla M, Burzynska M, Maniecka-Bryla I: Self-rated quality of life of citydwelling elderly people benefitting from social help: results of a crosssectional study. Health Qual Life Outcomes 2013, 11:181.

57. Charlson ME, Pompei P, Ales KL, Mackenzie CR: A new method of classifying prognostic comorbidity in longitudinal studies: development and validation. J Chronic Dis 1987, 40:373-383.

58. Quan H, Sundararajan V, Halfon P, Fong A, Burnand B, Luthi JC, Saunders $L D$, Beck CA, Feasby TE, Ghali WA: Coding algorithms for defining comorbidities in ICD-9-CM and ICD-10 administrative data. Med Care 2005, 43:1130-1139.

59. Folstein MF, Folstein SE, McHugh PR: "Mini-mental state" : A practical method for grading the cognitive state of patients for the clinician. J Psychiatr Res 1975, 12:189-198.

60. Engedal K, Haugen P, Gilje K, Laake P: Efficacy of short mental tests in the detection of mental impairment in old age. Compr Gerontol A 1988, 2:87-93.

61. Harrell LE, Marson D, Chatterjee A, Parrish JA: The severe mini-mental state examination: a new neuropsychologic instrument for the bedside assessment of severely impaired patients with Alzheimer disease. Alzheimer Dis Assoc Disord 2000, 14:168-175.

doi:10.1186/1471-2318-14-45

Cite this article as: Helvik et al: A 52 month follow-up of functional decline in nursing home residents - degree of dementia contributes. BMC Geriatrics 2014 14:45.

\section{Submit your next manuscript to BioMed Central and take full advantage of:}

- Convenient online submission

- Thorough peer review

- No space constraints or color figure charges

- Immediate publication on acceptance

- Inclusion in PubMed, CAS, Scopus and Google Scholar

- Research which is freely available for redistribution 